\title{
Hospital Performance: Efficiency or Quality? Can we have both with IT?
}

\author{
Roya Gholami ${ }^{\mathrm{a} 1}$, Dolores Añón Higón ${ }^{\mathrm{b}}$, Ali Emrouznejad ${ }^{\mathrm{a}}$ \\ ${ }^{a}$ Aston Business School, United Kingdom \\ Aston Triangle, Birmingham B47ET, United Kingdom \\ Email: a.emrouznejad@aston.ac.uk \\ ${ }^{b}$ ERI-CES, University of Valencia, Spain
}

Facultad de Economía, Universidad de Valencia, Avda. de los Naranjos S/N, 46022 Valencia, Spain Email: m.dolores.anon@uv.es

\begin{abstract}
The influence of IT investment on hospital efficiency and quality are of great interest to healthcare executives as well as insurers. Few studies have examined how IT investments influence both efficiency and quality or whether there is an optimal IT investment level that influences both in the desired direction. Decision makers in healthcare wonder if there are tradeoffs between their pursuit of hospital operational efficiency and quality. Our study involving a 2-stage double bootstrap DEA analysis of 187 US hospitals over two years found direct effects of IT investment upon service quality and a moderating effect of quality upon operational efficiency. Further, our findings indicate a U-shaped relationship between IT investments and operational efficiency suggesting that IT investments have diminishing returns beyond a certain point.
\end{abstract}

Keywords: Information Technology, Operations Management, Hospital, Efficiency, Quality

\footnotetext{
${ }^{1}$ Corresponding Author

Address: Aston University, Aston Triangle, Birmingham B47ET, United Kingdom

Email: r.gholami@aston.ac.uk

Phone:+44(0)121 2043103
} 


\section{Introduction}

Thirty-two million more Americans are expected to join the US health insurance rolls by 2019 (Congressional Budget Office, 2010). Under the Affordable Care Act of 2010, there will be changes in payment rates to providers that will put considerable pressure on hospitals' operating margins (Annual report of the Boards of Trustees of the Federal Hospital Insurance and Federal Supplementary Medical Insurance Trust Funds, 2010) ${ }^{2}$ requiring them to align their operating budgets with constrained reimbursement rates (Folland et al., 2010). Given these harsh financial conditions, it will be difficult for hospitals to add beds or to increase staffing for patients (Truffer et al., 2010) so hospitals in US need to become more efficient in order to lower costs and increase efficiency to care for patients (Litvak and Bisognano, 2011) while also continuing to enhance quality of patient care.

During the last few years, healthcare spending in developed countries had grown much faster than GDP (OECD 2013). Only in 2013 for instance, healthcare spending was 7-18\% of GDP in developed countries (OECD 2013; Martin et al., 2014). Recent studies suggest if increases in healthcare costs are inevitable, the focus should shift from cost reduction to improving healthcare quality (Thompson et al., 2014). To achieve these goals, hospitals have adopted various approaches such as greater automation and coordination through the use of information technology (IT). IT increases productivity by making tasks more efficient (Brynjolfsson and Hitt, 1996; 2000; Mittal and Nault, 2009). Even though recent studies find IT spending seems to lead to better health outcomes (Jones et al., 2014), the adoption and use

\footnotetext{
${ }^{2}$ http://www.cms.gov/Research-Statistics-Data-and-Systems/Statistics-Trends-andReports/ReportsTrustFunds/downloads/tr2010.pdf
} 
of IT have been slow by healthcare industry (Herzlinger, 2006; Jha et al., 2009). However, in recent years, due to rising healthcare costs and demands for higher quality, hospitals have invested in healthcare IT in order to reduce costs and errors, and improve quality of healthcare (Datamonitor, 2008; Das et al., 2011). In 2011, \$519 billion was allocated for healthcare IT in the U.S. following the stimulus bill (Das et al., 2011), A similar trend was observed in Western Europe, where healthcare IT spending was increasing from $\$ 9$ billion in 2006 to $\$ 12$ billion in 2011 (IDC Report 2008).

There is a sizable literature investigating the business value of IT for different industries. However, the business value of IT in healthcare is still to be fully investigated (Devaraj et al., 2013; Haddad and Wickramasinghe, 2014). Demonstrable return on investment for healthcare IT is essential to convincing hospital managers that IT investment can improve their performance. Hospital managers must also decide how and where to deploy IT - in quality enhancing initiatives or efficiency bearing initiatives, or both? Given mounting pressures to control costs, and because IT constitute a significant cost, managers must understand the available choices in order to make appropriate IT investment decisions (Salge, 2011).

Since the new initiatives are beginning to evaluate healthcare quality, an understanding of factors that can lead to improved quality is important. For instance, the Health Information Technology for Economic and Clinical Health (HITECH) Act encourages hospitals to improve operational efficiency and healthcare quality by adopting healthcare information systems. Hospitals will receive Medicare (a U.S. government program for elderly citizens) and Medicaid incentive payments when they use healthcare information systems in order to achieve "meaningful use" objectives with respect to healthcare quality. 
Previous research has emphasized the need for adopting quality management practices together with healthcare information systems for efficient use of hospital beds (Mango and Shapiro, 2001, Büyüközkan et al., 2011, Büyüközkan and Çifçi 2012), for example, to prevent adverse drug events that result in reduced patient length of stay (Davenport and Glaser, 2002). Quality in hospitals is generally manifested as patients' medical complications and mortality. Hospitals benchmark their complications and mortality with 'expected' levels that are adjusted for patients' demographic mix and severity. The cause of patient complications can be often traced to patient care process failures resulting from inefficient or poor coordination. Complications not only increase hospital costs but can also result in harm to the patients and in the worst-case scenario result higher mortality rates.

Previous research has empirically investigated the relationship between operational efficiency and healthcare quality but the findings are mixed. A report prepared for the Agency for Healthcare Research and Quality (AHRQ 2006) and a review paper (Chaudhry et al., 2006) found some evidence of cost reduction and quality improvement through healthcare IS in a few hospitals. However, the results were not generalizable. Few studies that have addressed the relationship between hospital efficiency and quality have arrived at conflicting conclusions. For instance, some studies have found a positive association between operational efficiency and healthcare quality in hospitals (Carey and Burgess, 1999, Nayar and Ozcan, 2008, Clement et al., 2008) while others have found a negative association (Morey et al., 2009, Maniadakis et al., 2009) leaving the possibility that there may be a balance that can be struck.

Quality guru Deming proposed that constantly improving the system of production and service by most up-to-date process improvement techniques and to critically re-examine care processes, simplify process flows, and consequently improve operational efficiency and 
quality (Deming 1986). Similarly Crosby (1979) proposed that the optimal quality level is zero defects which is based on the belief that producing higher quality products is always less costly than producing low quality products. This has led to the famous claim that quality is "free."

The first research question driving this study is "Can hospitals improve their operational efficiency as well as healthcare quality by investments in information systems?" Further, we identify the interplay of efficiency and quality and identify characteristics of the hospitals that can better take advantage of their IT investments. Hence, the second research question is, "What is the optimal balance of efficiency and quality relative to IT investment? In other words, "What is the 'sweet spot' of IT investment at which both operational efficiency and service quality are maximized?"

In addition to seeking answers to the above research questions, we aim to contribute to the literature with an alternative methodological approach based upon a two-stage double bootstrap data envelopment analysis (DEA), in line with Simar and Wilson (2007). In the first stage, we use DEA to estimate efficiency scores for 187 US hospitals for 2004 and 2005. Since there are multi-input and multi-output in the case of hospital production process, we choose a DEA approach in order to measure hospital efficiency. This approach allows us to take the heterogeneity of output into account. The DEA approach also enables us to investigate changes in input mix and the consequent savings from reducing operational inefficiency and improving healthcare quality. This helps managers and policy makers identify sources of operational inefficiency in relation to the quality improvements in hospitals. Despite the popularity of DEA to measure efficiency in hospitals, few studies have used bootstrapping to account for measurement errors in estimates, the exceptions being Staat (2006) and Araújo et al. (2014), among others. In the second stage, efficiency scores are 
treated as a function of IT, service quality and other determinants of efficiency in healthcare such as teaching status, case mix and location. Following, previous studies (e.g. Barros and Peypoch, 2009; Araújo et al., 2014), a bootstrapped truncated regression is used to estimate the relationship between efficiency scores and its determinants.

The rest of the paper is organized as follows. Section 2 provides the theoretical background on IT and healthcare efficiency and quality. Section 3 gives an overview of the data followed by empirical model and the variables that enter into the empirical analysis in Section 4. Main findings and discussion of findings are presented in Section 5 and Section 6 respectively. Finally, Section 7 provides some concluding remarks.

\section{Theoretical Background}

\subsection{Impact of IT on Hospital Efficiency or/and Quality}

There are two rival theories on the relationship between quality and efficiency. Juran and Gryna (1980) develop the concept of an optimal quality level by trading off the appraisal and prevention costs. They argue that the optimal quality level implies a strictly positive proportion of defectives, and once the optimal quality level has been achieved, any attempt to improve further will actually lead to increased costs. On the other hand, Deming (1986) and Crosby (1979) argued that optimal quality level is zero defects and that zero defects don't increase the cost. In a later study, Fine (1986) tried to resolve the disagreement between these two rival theories and developed a model in order to show that when quality-based learning affects quality control costs, firms have the motivation to target zero defects. However, the findings of empirical studies support the interpretations of Deming and Crosby (Garvin 1983, Abernanthy et al. 1981, Hendricks and Singhal, 1996, 1997, 2000). 
The views of Crosby and Deming are relevant to improvements in operational efficiency and quality in healthcare as well. Deming proposed constantly improving the system of production by cutting-edge process improvement techniques; to critically re-examine care processes and simplify patient flows and consequently improve operational efficiency and healthcare quality. Business process redesigns (BPR) with the purpose of quality improvements has also been examined in the IT business value research (Grover et al., 1998).

For instance, Barua et al. (1996) proposed a theory of business value complementarity that argues IT investments and process redesign cannot succeed in isolation since IT and business process redesign are complementary factors (Devaraj and Kohli, 2000). Himmelstei et al. (2010), linked computerization data at approximately 4000 hospitals with administrative cost data (from Medicare Cost Reports) and cost and quality data (from the 2008 Dartmouth Health Atlas) and investigated whether more computerized hospitals had lower costs or higher healthcare quality levels. They compared hospitals included on a list of the "100 Most Wired" hospitals with others and found healthcare information systems modestly improves healthcare quality but does not reduce the costs.

$\mathrm{Wu}$ and $\mathrm{Hu}$ (2012) proposed a research model for exploring KM-enabled performance for hospital professionals and they found that hospital professionals were closely associated with KM-enabled performance in providing high-quality healthcare. More recently, Devarjaj et al. (2013) examined the role of IT on patient flow and its consequences for improved hospital efficiency and performance. They analyzed data from 567 hospitals in U.S. and the results suggested that IT was associated with swift and even patient flow, and consequently with improved revenues. Devarjaj et al. (2013) also found that the improvement in financial performance was not at the expense of quality. In another study, Menon and Kohli (2013) investigated the impact of past IT spending on the malpractice insurance premium and the 
moderating effect of past IT expenditure on the relationship between past malpractice insurance premium and current quality of healthcare. They found that past IT expenditure was negatively associated with malpractice insurance premium and positively associated with quality of patient care. More recently, Haddad and Wickramasinghe (2014) argued that there is no clear framework for assessing the business value of IT in healthcare. They proposed a framework for the evaluation of cost versus quality outcomes utilizing different layers within healthcare delivery.

\subsection{The Efficiency-Quality Trade-off in Hospitals}

Hospital managers wonder whether there is a tradeoff between operational efficiency and healthcare quality. Nayar and Ozcan (2008) argue that the answer to this question is far from resolved. When a hospital has efficient production, it is expected to operate at maximum output at minimum cost. Hence, operational efficiency is a measure of the know-how of the production process. On the other hand, poor healthcare quality points to problems with operational efficiency. Operational efficiency, in terms of eliminating waste, is one dimension of healthcare quality in hospitals. Healthcare quality and operational costs are parts of the equation for operational efficiency.

Previous literature has offered insights from analysis of empirical data. For example, studies have indicated that increases in registered nurses (in the nursing mix of hospitals) are positively associated with lower amounts of patient safety incidents (Haberfelde et al., 2005). Also, there is evidence that use of advanced technology is associated with higher service quality in healthcare (Dranove and White 1998; Picone et al. 2003). However, increases in nurses (staff) and advanced technology (capital) is costly. Therefore, it is likely that lower levels of operational efficiency (higher costs) and higher levels of healthcare quality are positively associated. Stressing the importance of this relationship, McKay and Deily (2005) 
call for more research on the trade-off between operational efficiency and service quality in healthcare. Below we review previous studies that have examined the efficiency-quality relationship.

McCloskey (1998), Blegen et al. (1998), and Blegen and Vaughan (1998) found that increasing the number of nurses improves healthcare quality, but only to a point, after which it decreases operational efficiency suggesting that too much of labor and capital inputs lead to lower operational efficiency and not necessarily to higher healthcare quality. Similarly, Picone et al. (2003) found that even though resources and capacity are inputs to quality, too much capacity will lead to lower operational efficiency in healthcare.

Valdmanis et al. (2008) claimed that reallocation of resources could potentially increase healthcare quality. More importantly, higher healthcare quality is not necessarily achieved as a result of higher costs or lower operational efficiency. Hvenegaard et al. (2011) summarize three different relationships between operational efficiency and healthcare quality based on the findings of the previous literature. Using patient level data, they estimate a fixed effect models for operational costs and healthcare quality for patients admitted to vascular surgery in six vascular departments and found that the relationship between cost and healthcare quality fluctuates depending on how the quality is measured. They found that lower costs (higher operational efficiency) tend to be associated with higher mortality (as a measure of lower quality), indicating an efficiency-quality trade off.

Hence, Hvenegaard et al. (2011) propose a U-shaped relationship between operational efficiency and healthcare quality. They argue, this U-shaped relationship explains the lack of agreement on the relationship between the two measures of performance found by previous empirical studies. The findings of previous studies depend on where hospitals lie along the U- 
shaped curve, and how quality was measured. Based on above discussion we test the following three propositions:

Proposition 1: Higher levels of IT investments are associated with higher levels of healthcare quality in hospitals.

Proposition 2: Higher levels of IT investments are associated with higher levels of operational efficiency in hospitals.

Proposition 3: Higher levels of IT investments and higher levels of healthcare quality are associated with higher levels of operational efficiency in hospitals.

\section{Data Sources}

The data for this study consist of a panel of 187 hospitals in the U.S. for the period 20042005. The first source of data is Solucient, Inc. (Thompson Reuters Healthcare) including financial, productivity, and expense data. Our second data source is the Delta Group that provides data on clinical, financial, and market performance of hospitals. Our data set represents the two year period for which all relevant data fields were presented in both databases.

Information Technology (IT): The source for IT expenditure (direct expenses for information processing but not clinical or diagnostic technologies), is the Solucient Inc., database. IT expenditure variable includes expenses on information systems that are related to direct patient care and covers IT hardware, software, and services.

Hospital Quality: Measures of hospital quality that are normally used by previous literature are "risk-adjusted mortality" and "complications" to explain the differences in the patients. The variable "complications" measures expected complications during a patient's stay. "Mortality" on the other hand is defined as the number of mortalities within 30 days of an operative procedure divided by the total number of operative procedures conducted in the 
time period under consideration. In order to estimate these measures, the Delta Group employs national clinical and financial data included in Medicare cases discharged from all general, acute, non-federal U.S. hospitals. The "expected" measures are sold to hospitals as a valid benchmark of complications/mortality during a patient's stay in hospital.

The Risk-adjusted mortality index (RAMI) tries to measure the extent to which a provider's inpatient mortality rate is higher or lower than expected for specific diagnoses and procedures given the risk factors of the patient population, and where an index of 1.00 indicates that the actual mortality rate equals the expected rate. On the other hand, the Risk-adjusted complication index (RACI) attempts to measure to what extent a provider's postsurgical and post-obstetrical complication rates during a hospital stay are higher or lower than expected for particular diagnoses and procedures, given the risk factors of the patient population. In this case an index of 1.00 indicates that the actual complication rate is equal to the expected rate. In addition, we obtain a non-adjusted measure of quality in terms of complications and mortality (RACI and RAMI) as the difference between the actual and the estimate rate of complications and mortality, respectively. We use the adjusted and unadjusted measure as a test of robustness.

Hospital Efficiency: Efficiency can refer to either "technical efficiency" or "cost efficiency". Technical efficiency is related to the term productivity. Cost efficiency, instead, takes the costs of inputs into account and describes how much a hospital spends on its inputs to produce a given level of output. In this paper, we refer to technical efficiency, which characterizes efficient behavior to minimize inputs used for a given level of output or maximizing output for a given level of inputs in a hospital.

Case Mix Index: The Case Mix Index (CMI) measures how costly and complex inpatients are. The higher the case-mix, the more complex the services offered by the hospital. This 
captures the hospital-specific systematic variance due to expertise and specialized services. A hospital's CMI is calculated for reimbursement for services by Medicare.

Teaching Status: Teaching status is a dummy variable representing a teaching hospital versus non-teaching hospital. Teaching hospitals are more likely to have high-tech medical equipment, higher funding, higher expertise of personnel, and higher severity of cases. The teaching status controls for differential access to technology and expertise within hospital.

Hospital Location: Similar to teaching status variable, location is a dummy variable which takes a value 1 for urban and 0 for rural areas. Location is expected to impact the types of cases that a hospital takes more frequently.

Hospital Size: Larger hospitals benefit from economies of scale, which are expected to result in a lower resident cost per day. Larger hospitals also have greater resources that can result in a better management and staffing profile which can eventually impact healthcare quality. The hospital's sizes are approximated by the number of adjusted full time employees and divided into 3 band-categories ${ }^{3}$.

\section{Empirical Model}

\subsection{Stage 1: Estimating Technical Efficiency}

A firm uses different kinds of inputs such as capital, labour, materials and produces outputs through a "production process". The production frontier specifies the maximum output achievable by employing a combination of inputs. The distance between the maximum output and the actual output is regarded as its "technical inefficiency". Therefore, a technically

\footnotetext{
${ }^{3}$ Size 1 refers to hospitals with less than 500 full time employees, size 2 to those between 500 and 1000 ; and size 3 refers to those hospitals with more than 1000 .
} 
inefficient firm operates below the frontier and a technically efficient firm operates on the production frontier.

The two well-known modelling methods of comparative performance measurement are "nonparametric" method, characterized by Data Envelopment Analysis (DEA) and "parametric" approach, characterized by Stochastic Frontier Analysis (SFA). Both DEA and SFA approaches are derived from the methods of measuring efficiency introduced by Farrell (1957) who suggested measuring the production efficiency of a firm relative to an empirical production frontier. The parametric approach (SFA), involves the assumption of a functional form (e.g. Cobb-Douglas, translog, CES, etc.) to be made for the production frontier. It uses statistical methods to estimate the coefficients of the production function as well as the technical efficiency (Lovell, 1993). A potential disadvantage of this method is the misspecification of a functional form for the production process. On the other hand, nonparametric production frontiers are based on deterministic mathematical programming and do not make any assumptions about the functional form (Charnes et al., 1985, Giraleas et al., 2012). The data points are compared with one another for determining efficiency and the most efficient observations are used to construct the piece-wise linear convex non-parametric frontier. Consequently, non-parametric production frontiers are employed to measure relative technical efficiency among observations.

Both approaches have well known advantages and disadvantages. The DEA, as developed by Charnes et al. (1978) enable measurement of efficiency for production units (such as hospitals here), using multiple inputs to produce multiple outputs, and it is free of functional assumption but does not control for the random changes. DEA has been used in variety of applications both in public and private sectors (see Emrouznejad and De Witte, 2010, Lin et al., 2009, De Nicola et al., 2012). The SFA method, however, takes into account the random 
changes by decomposing the total stochastic term into the firm related and out-of-control factors, but imposes strong assumption on the production process and the error distribution.

Assume that an output-oriented DEA model consists of input variables $\left(X_{1}, \ldots, X m\right)$ and output variables $\left(Y_{1}, \ldots, Y_{S}\right)$ with $n$ decision making units $(j=1, \ldots, n)$. The model builds the additive combinations of outputs and inputs to achieve single virtual output and virtual input in the calculation of an efficiency score.

\section{$\operatorname{Max} \alpha$}

s.t.

$$
\begin{aligned}
& \sum_{j=1}^{n} \lambda_{j} x_{i j} \leq \alpha x_{i j_{0}} ; \quad \forall \mathrm{i}=1, \ldots, \mathrm{m} \\
& \sum_{j=1}^{n} \lambda_{j} y_{r j} \geq y_{r j_{0}} ; \quad \forall \mathrm{r}=1, \ldots, \mathrm{s} \\
& \sum_{j=1}^{n} \lambda_{j}=1 \\
& \lambda_{j} \geq 0 \quad ; \quad \forall \mathrm{j}=1, \ldots, \mathrm{n}
\end{aligned}
$$

Investigating the impact of IT on operational efficiency and healthcare quality is challenging since healthcare is a service industry and input-output variables for production function must be defined very carefully in service industries. Our analysis begins with estimating measures of efficiency, technical change, and productivity for each hospital in the sample. DEA has been widely used in assessing health care centers and hospitals (for example see Field and Emrouznejad, 2003, Kirigia, et al., 2008 and Hollingsworth, 2008). Input and output variables used in this paper are similar to those used in the previous hospital efficiency literature. Output is defined as income and health services. Four direct hospital outputs were specified including: NPR (net patient revenue), IPRev (total inpatient revenue), Admisn (total number of admissions), and IPDays (total number of patient days). 
For the input set, four variables representing resource consumption are defined: AG_sum (administrative and general direct expenses and salaries), SalWg (salaries wages and fees payable, e.g. for temporary nurses), FTEadj (total number of full time employees), Asst (sum of total current and total long-term assets of the hospital, total assets is a measure of a hospital's size) and Beds (total number of beds in service). A summary of all variable definitions is provided in Table 1. Note that the first three inputs are labor while the last two are proxy for net capital assets, as suggested by Grosskopf and Valdmanis (1987). For the efficiency scores we used radial measure as calculated by DEA-bootstrapping two-stage approach under variable returns to scale. The bootstrapping procedure applied in this study is based on Simar and Wilson's (2007) to construct estimated confidence intervals for each hospital. 
Table 1: Summary Statistics for Stage 1 and Stage 2

\begin{tabular}{|c|c|c|c|c|c|}
\hline Variable & Description & Mean & s.d. & Min & Max \\
\hline \multicolumn{6}{|c|}{$1^{\text {st }}$ Stage Analysis } \\
\hline$N P R^{*}$ & net patient revenue & 172 & 165 & 10.2 & 1210 \\
\hline IPRev* & total inpatient revenue & 300 & 387 & 9.49 & 3780 \\
\hline Admisn & total number of admissions & 11983.8 & 9295.7 & 365 & 44863 \\
\hline IPDays & total number of patient days & 68322.5 & 52621.0 & 3057 & 264736 \\
\hline$A G \_$sum* & $\begin{array}{l}\text { administrative and general direct expenses and } \\
\text { salaries }\end{array}$ & 31.5 & 33.7 & 1.69 & 367 \\
\hline SalWg * & $\begin{array}{l}\text { salaries wages and fees payable, e.g. for } \\
\text { temporary nurses }\end{array}$ & 7.36 & 8.47 & 0.061 & 76.6 \\
\hline FTEadj & total number of full time employees & 1445.46 & 1385.48 & 45 & 13999 \\
\hline Asst* & $\begin{array}{l}\text { sum of total current and total long-term assets } \\
\text { of the hospital, total assets is a measure of a } \\
\text { hospital's size }\end{array}$ & 89.1 & 101 & -110 & 546 \\
\hline Beds & total number of beds in service & 269.39 & 177.94 & 21 & 901 \\
\hline$E F$ & Efficiency score (DEA) & 0.896 & 0.110 & 0.424 & 1.000 \\
\hline \multicolumn{6}{|c|}{$2^{\text {nd }}$ Stage Analysis } \\
\hline $\ln (I T)$ & $\begin{array}{l}\text { IT expenditures for direct patient care, salary } \\
\text { of IT employees and for other services }\end{array}$ & 1.528 & 1.248 & -2.396 & 4.733 \\
\hline $\ln (I T p c)$ & IT expenditures for direct patient care & 0.800 & 1.257 & -3.089 & 3.488 \\
\hline$C M I$ & Case Mix Index & 1.425 & 0.261 & 0.523 & 2.243 \\
\hline rel avg wage & Relative average wage & 1.049 & 0.459 & 0.010 & 3.783 \\
\hline$o c c \_r t$ & Occupancy rate & 242.837 & 55.673 & 85.396 & 406.094 \\
\hline revenue _ppd & Revenues per patient day (in thousands) & 3.877 & 2.741 & 0.481 & 24.704 \\
\hline Urban & Dummy coded 1 if hospital is urban & 0.759 & 0.428 & 0.000 & 1.000 \\
\hline Teach & Dummy coded 1 if teaching hospital & 0.455 & 0.499 & 0.000 & 1.000 \\
\hline Calos & Length of stay & 4.183 & 0.617 & 2.550 & 6.670 \\
\hline Size & $\begin{array}{l}\text { Size broken down into size bands (small }=1- \\
\text { 499; medium=500-999; large }>=1000 \\
\text { employees) }\end{array}$ & 2.425 & 0.738 & 1.000 & 3.000 \\
\hline RAMI & Risk adjusted mortality index & 0.940 & 0.270 & 0.000 & 1.830 \\
\hline$R A C I$ & Risk adjusted complications index & 0.979 & 0.322 & 0.000 & 2.270 \\
\hline$R M I$ & Unadjusted mortality index (actual/ predicted) & 0.951 & 0.253 & 0.000 & 1.830 \\
\hline$R C I$ & $\begin{array}{l}\text { Unadjusted complication index (actual/ } \\
\text { predicted) }\end{array}$ & 0.975 & 0.316 & 0.304 & 2.250 \\
\hline
\end{tabular}

Note: * figures are in US\$ millions.

Table 2: Descriptive Statistics (Stage 1)

\begin{tabular}{ccc} 
& Mean & $\begin{array}{c}\text { Standard } \\
\text { Deviation }\end{array}$ \\
\hline Technical Change & 0.993 & $(0.035)$ \\
\hline Total Factor Productivity Growth & 0.991 & $(0.079)$ \\
\hline $1^{\text {st }}$ Efficiency (2004) & 0.905 & $(0.106)$ \\
$2^{\text {nd }}$ Efficiency (2005) & 0.887 & $(0.112)$ \\
\hline
\end{tabular}




\subsection{Determinants of Quality in Hospitals}

To analyze the relationship between IT and healthcare quality as stated in Proposition 1, we estimate the following reduced form model, in which we regress healthcare quality on IT and other factors affecting quality. In estimating such a model it is important to control for scale economies through hospital size and other factors.

$Q_{i t}=\alpha_{i}+\beta I_{i t}+\gamma X_{i t}+\varepsilon_{i t}$

where $Q_{i t}$ is a measure of quality for hospital $i$ and time $t, I_{i t}$ represents IT investment, $X_{i t}$ is a vector of other variables pertaining to the hospital (including size, teaching, urban, risk perception), as well as differences in patient case mix. According to our assumption, we expect the sign of the coefficient $\beta$ to be negative and significant, implying that and increase in IT investment will lead to lower risk, or in other words, higher quality (measured as the ratio between actual and predicted).

\subsection{Stage 2: Examining Determinants of Efficiency}

To test Propositions 2 and 3, we estimate different specifications in which our dependent variable is the first-stage DEA efficiency scores, as in previous studies (e.g. Barros and Peypoch, 2009; Merkert et al., 2010; Araújo et al., 2013). In particular, to test Proposition 2, we propose a U-shaped relationship between IT's and hospital's efficiency (see Hvenegaard et al. 2011). In doing so, we regress the first-stage bootstrapped DEA efficiency scores against IT investment, its squared term and a set of control variables assumed to determine hospital's efficiency. The estimated models can be expressed by the following general formulation:

$\hat{E}_{i t}=\alpha+\beta_{1} I_{i t}+\beta_{2} I_{i t}^{2}+Z_{i t} \gamma+\varepsilon_{i t}$ 
where $\hat{E}_{i t}$ represents the bias corrected DEA efficiency scores for hospital $i$ and time $t, I_{i t}$ represents IT spending, $Z_{i t}$ is a vector of control variables and $\varepsilon_{i t}$ is an error term. In this specification, according to the U-shaped relationship we expect $\beta_{1}$ to be negative and $\beta_{2}$ to be positive. Finally, to test Proposition 3, we slightly modify Equation (2) to add the quality variable $\left(Q_{i t}\right)$ as explanatory variable. Therefore, our final model may be specified as:

$$
\hat{E}_{i t}=\alpha+\beta_{1} I_{i t}+\beta_{2} I_{i t}^{2}+\delta_{1} Q_{i t}+Z_{i t} \gamma+\varepsilon_{i t}
$$

Due to the limited nature of the efficiency measure, a (censored) Tobit model has traditionally been used to estimate equations (2) and (3). However, Simar and Wilson (2007, 2011) argue that the use of a Tobit regression in a two-stage analysis in which the dependent variable is "estimated" rather than observed is inappropriate. First, the efficiency scores estimated by DEA may be correlated with each other. As a consequence the error term in the Tobit model is serially correlated and standard inference is not valid unless some form of bootstrapping is used. Second, in small samples, the explanatory variables used in regression analysis may be correlated with the variables used for calculating the DEA efficiency scores, causing correlation between the error term and the explanatory variables of the second stage.

To sidestep these controversial issues, following Simar and Wilson $(2007,2011)$, we apply a bootstrap truncated regression. In doing so, the error term in equations (2) and (3), is assumed to follow a truncated normal distribution with zero mean (before truncation), unknown variance and a left truncation point. Alternatively, for comparative purposes we present also results for a bootstrap tobit model in which DEA scores are bootstrapped in the first stage to obtain bias corrected efficiency scores, and then the second step is performed on the bases of the bootstrap-tobit regression. 


\section{Estimation Results}

\subsection{IT as Determinant of Healthcare Quality}

In Table 3, the results of estimating equation (1), which tests for Proposition 1, are presented. In this case, IT and quality are linearly related ${ }^{4}$. An alternative non-reported model specification rejected the non-linear relationship. Results in column (1) and (3) are the baseline specification for both measures of quality in terms of mortality and complications respectively (RAMI and RACI). In the case of quality in terms of risk-adjusted mortality (RAMI) we find a positive and significant relationship between IT and quality (column 1).

The negative sign of the IT coefficient implies that higher the IT investment, lower is the mortality index, and therefore higher the quality. As regards to other control variables, the case mix (CMI) negatively affects quality and teaching hospitals appear to experience a lower quality than non-teaching hospitals. In column (2) we further control for additional variables. The results confirm the positive impact of IT on quality. The results also show that the length of stay exert a negative effect on quality. In column (3), we present the results for the baseline specification in which the dependent variable is a measure of quality in terms of complications. In this case, the relationship between IT and quality appears non-significant. In column (4), the previous non-significant relationship between IT and quality in terms of complication appears robust to the inclusion of additional control variables. Therefore, our results suggest that IT has a positive and significant relationship with quality only in the case of mortality but not in the case of complications.

\footnotetext{
${ }^{4}$ We ran a specification in which the squared term of IT was included, but this came up as not significant, suggesting that the true relationship was linear.
} 
Table 3. Relationship between IT and Quality: A Tobit Model

\begin{tabular}{|c|c|c|c|c|}
\hline Dependent Variable & RAMI & RAMI & RACI & RACI \\
\hline & (1) & (2) & (3) & (4) \\
\hline \multirow[t]{2}{*}{ IT (in logs) } & $-0.058 * * *$ & $-0.040 * *$ & 0.017 & 0.037 \\
\hline & $(0.015)$ & $(0.017)$ & $(0.019)$ & $(0.025)$ \\
\hline \multirow[t]{2}{*}{ CMI } & $0.265^{* * *}$ & $0.443 * * *$ & $0.280 * * *$ & $0.300 * * *$ \\
\hline & $(0.076)$ & $(0.090)$ & $(0.089)$ & $(0.092)$ \\
\hline \multirow[t]{2}{*}{ Urban } & -0.019 & $-0.117 * * *$ & -0.047 & -0.038 \\
\hline & $(0.032)$ & $(0.033)$ & $(0.036)$ & $(0.040)$ \\
\hline \multirow[t]{2}{*}{ Teaching } & $0.068 *$ & 0.008 & 0.028 & 0.028 \\
\hline & $(0.040)$ & $(0.034)$ & $(0.036)$ & $(0.037)$ \\
\hline \multirow[t]{2}{*}{ RACI } & -0.042 & -0.029 & & \\
\hline & $(0.046)$ & $(0.038)$ & & \\
\hline \multirow[t]{2}{*}{ RAMI } & & & -0.037 & -0.021 \\
\hline & & & $(0.054)$ & $(0.059)$ \\
\hline \multirow[t]{2}{*}{ Medium-sized } & & -0.006 & & $-0.086^{*}$ \\
\hline & & $(0.043)$ & & $(0.048)$ \\
\hline \multirow[t]{2}{*}{ Large-sized } & & 0.007 & & -0.101 \\
\hline & & $(0.053)$ & & $(0.066)$ \\
\hline \multirow[t]{2}{*}{ rel_avg wage } & & 0.025 & & $-0.061 *$ \\
\hline & & $(0.027)$ & & $(0.032)$ \\
\hline \multirow[t]{2}{*}{ revenue_ppd } & & -0.008 & & -0.006 \\
\hline & & $(0.010)$ & & $(0.006)$ \\
\hline \multirow[t]{2}{*}{ Calos } & & $0.219 * * *$ & & -0.006 \\
\hline & & $(0.034)$ & & $(0.030)$ \\
\hline \multirow[t]{2}{*}{ Year 2005} & $-0.058 *$ & $-0.055 * *$ & -0.049 & -0.043 \\
\hline & $(0.031)$ & $(0.026)$ & $(0.032)$ & $(0.032)$ \\
\hline Observations & 374 & 374 & 374 & 374 \\
\hline Log likelihood & -127.55 & -85.70 & -134.82 & -131.48 \\
\hline Sigma & $0.25 * * *(0.024)$ & $0.21 * * *(0.018)$ & $0.25 * * *(0.025)$ & $0.25 * * *(0.025)$ \\
\hline
\end{tabular}

Notes: "Dependent variable is quality in terms of mortality $(R A M I)$ and in terms of complications $(R A C I)$; which have been normalized to $0-1$. Standard errors in parentheses.

$*$ denotes significance at $10 \%$ level, $* *$ at $5 \%$ level, and $* * *$ at $1 \%$ level 


\subsection{Determinants of Efficiency: IT and Quality}

In Table 4 we present the results of estimating Equation (2) and testing for Proposition 2. For comparative purposes, column (1) and (2) presents the results from a bootstrap Tobit model while those from columns (3) and (4) are those from a bootstrap truncated regression. Results reveal that while the signs of the parameters are maintained, their values change significantly. In column (1) and (3) the baseline specification is presented, in which we regress IT, ITsquared and other controls on efficiency. The results confirm the non-linear U-shaped relationship between IT and efficiency. The coefficients on IT as well as IT-squared are highly significant, and while the coefficient on IT is negative, the coefficient on IT-squared is positive. This means that the relationship between IT and efficiency is non-linear. At low levels of IT investment the relationship is negative, but there is a threshold level of IT at which the relationship becomes positive. Moreover, the differentiation of equation (2) with respect to IT yields the slope of the relationship between efficiency and IT. If we calculate the point at which the slope of this relationship is zero, we will have identified the minimum or turning point, of the IT-efficiency relationship.

On the basis of the results of the double bootstrap truncated regression (column (3)), differentiation of the estimated Equation (2) with respect to IT: $(E / I T=-0.049+0.018 I T)$ suggests that the slope of the IT-efficiency relationship depends on the level of IT. At low levels of IT spending the slope is negative, such that efficiency falls with IT spending. The point at which the IT-efficiency reaches its minimum is calculated by setting ( $E / I T=0)$. That indicates the efficiency minimizes where, $-0.049+0.018 I T=0$ namely when $I T$ (in $\log$ levels) equal to 2.722 or equivalently, it appears that the level of IT expenditure at which the minimum occurs is of fifteen million dollars (i.e. $\exp (2.722)=15.21)$. 
This level of IT spending is well above the average, what implies the need for hospitals to surpass a high level of IT spending from which additional IT spending brings efficiency improvements. In Figure 2 we present this U-shaped relationship between the predicted efficiency levels and IT together with its 95\% confidence interval. The graph is based on the estimates presented in column (3) of Table 4. The downward slope in the U-shaped curve indicates a negative relationship between lower IT investment and lower efficiency in healthcare, up to a threshold IT level (2.722) at which the impact of IT on hospital efficiency becomes positive (point Min in Figure 2). In our sample, there are 42 hospitals above that threshold level of IT investment. These hospitals are characterized by being large, mostly urban and teaching hospitals.

Figure 2: U-shaped relationship between IT and Healthcare Efficiency

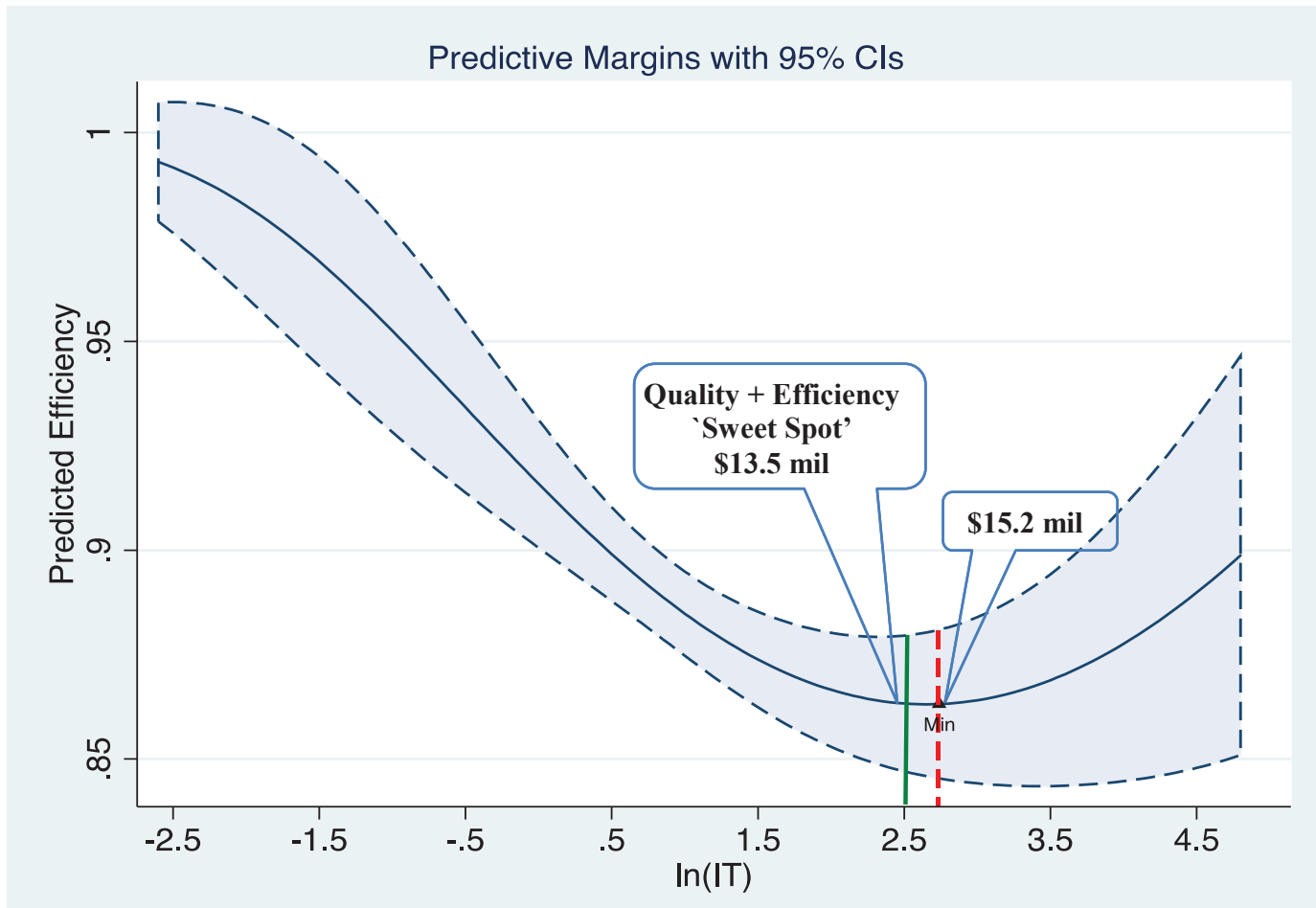


In addition, the results show that the relative average wage and the length of stay have a negative and significant impact on efficiency. On the other hand, the occupancy rate and the revenue per patient per day have a positive and significant effect on efficiency. With respect to size, medium sized hospitals appear less efficient vis-à-vis small hospitals. In columns (2) and (4), the IT variable (IT $\left.\_c\right)$ covers only IT expenses for direct patient care (and excludes expenses for salary of IT employees as well as expenses for other services as consulting, supplies, etc.). Results obtained in columns (1) and (3) are confirmed: namely IT and efficiency convey a U-shaped relationship. 
Table 4. U-shaped relationship between IT and Efficiency

\begin{tabular}{|c|c|c|c|c|}
\hline \multirow[b]{2}{*}{$\begin{array}{l}\text { Dependent } \\
\text { Variable }\end{array}$} & \multicolumn{2}{|c|}{ Bootstrap Tobit } & \multicolumn{2}{|c|}{ Bootstrap Truncated Regression } \\
\hline & $\begin{array}{c}\text { Efficiency } \\
(1) \\
\end{array}$ & $\begin{array}{c}\text { Efficiency } \\
(2) \\
\end{array}$ & $\begin{array}{c}\text { Efficiency } \\
(3) \\
\end{array}$ & $\begin{array}{c}\text { Efficiency } \\
(4) \\
\end{array}$ \\
\hline IT (in logs) & $\begin{array}{c}-0.083 * * * \\
(0.030)\end{array}$ & & $\begin{array}{c}-0.049 * * * \\
(0.012)\end{array}$ & \\
\hline$I T^{2}$ (in logs) & $\begin{array}{c}0.016^{* * *} \\
(0.007)\end{array}$ & & $\begin{array}{c}0.009 * * * \\
(0.003)\end{array}$ & \\
\hline IT $\_c($ in $\log s)$ & -- & $\begin{array}{c}-0.046^{* * * *} \\
(0.017)\end{array}$ & -- & $\begin{array}{c}-0.030 * * * \\
(0.008)\end{array}$ \\
\hline IT $p c^{2}($ in $\log s)$ & -- & $\begin{array}{c}0.016^{* *} \\
(0.007)\end{array}$ & -- & $\begin{array}{c}0.009 * * * \\
(0.003)\end{array}$ \\
\hline$C M I$ & $\begin{array}{l}-0.017 \\
(0.045)\end{array}$ & $\begin{array}{l}-0.025 \\
(0.046)\end{array}$ & $\begin{array}{c}0.023 \\
(0.029)\end{array}$ & $\begin{array}{c}0.018 \\
(0.031)\end{array}$ \\
\hline Urban & $\begin{array}{l}-0.015 \\
(0.021)\end{array}$ & $\begin{array}{l}-0.016 \\
(0.021)\end{array}$ & $\begin{array}{l}-0.021 \\
(0.014)\end{array}$ & $\begin{array}{l}-0.022 \\
(0.015)\end{array}$ \\
\hline Teaching & $\begin{array}{c}0.007 \\
(0.019)\end{array}$ & $\begin{array}{c}0.005 \\
(0.018)\end{array}$ & $\begin{array}{c}0.004 \\
(0.013)\end{array}$ & $\begin{array}{c}0.004 \\
(0.013)\end{array}$ \\
\hline rel_avg wage & $\begin{array}{c}-0.055^{* * * *} \\
(0.018)\end{array}$ & $\begin{array}{c}-0.054 * * * \\
(0.018)\end{array}$ & $\begin{array}{c}-0.032 * * * \\
(0.011)\end{array}$ & $\begin{array}{c}-0.032 * * * \\
(0.011)\end{array}$ \\
\hline occupancy_rate & $\begin{array}{c}0.002 * * * \\
(0.000)\end{array}$ & $\begin{array}{c}0.002 * * * \\
(0.000)\end{array}$ & $\begin{array}{c}0.001 * * * \\
(0.000)\end{array}$ & $\begin{array}{c}0.001 * * * \\
(0.000)\end{array}$ \\
\hline revenue_ppd & $\begin{array}{c}0.021 * * * \\
(0.004)\end{array}$ & $\begin{array}{c}0.019 * * * \\
(0.004)\end{array}$ & $\begin{array}{c}0.010 * * * \\
(0.002)\end{array}$ & $\begin{array}{c}0.009 * * * \\
(0.002)\end{array}$ \\
\hline Calos & $\begin{array}{c}-0.039 * * \\
(0.016)\end{array}$ & $\begin{array}{c}-0.033 * * \\
(0.017)\end{array}$ & $\begin{array}{l}-0.013 \\
(0.010)\end{array}$ & $\begin{array}{l}-0.011 \\
(0.011)\end{array}$ \\
\hline Medium & $\begin{array}{c}-0.073 * * \\
(0.037)\end{array}$ & $\begin{array}{c}-0.085 * * \\
(0.035)\end{array}$ & $\begin{array}{l}-0.043^{*} \\
(0.022)\end{array}$ & $\begin{array}{c}-0.049 * * \\
(0.022)\end{array}$ \\
\hline Large & $\begin{array}{l}-0.050 \\
(0.043)\end{array}$ & $\begin{array}{l}-0.073^{*} \\
(0.040)\end{array}$ & $\begin{array}{l}-0.023 \\
(0.025)\end{array}$ & $\begin{array}{l}-0.035 \\
(0.024)\end{array}$ \\
\hline Year_2005 & $\begin{array}{c}-0.031 * * \\
(0.014)\end{array}$ & $\begin{array}{c}-0.033^{* *} \\
(0.014)\end{array}$ & $\begin{array}{c}-0.019^{* *} \\
(0.009)\end{array}$ & $\begin{array}{c}-0.020^{* *} \\
(0.009)\end{array}$ \\
\hline Sigma & $\begin{array}{c}0.121 * * * \\
(0.006)\end{array}$ & $\begin{array}{c}0.122 * * * \\
(0.006)\end{array}$ & $\begin{array}{c}0.088^{* * * *} \\
(0.003)\end{array}$ & $\begin{array}{c}0.088^{* * * *} \\
(0.003)\end{array}$ \\
\hline $\begin{array}{l}\text { Log likelihood } \\
\text { Wald } \chi^{2}\end{array}$ & $\begin{array}{c}69.387 \\
152.634 * * *\end{array}$ & $\begin{array}{c}65.567 \\
155.994 * * * \\
\end{array}$ & $\begin{array}{c}378.419 \\
140.421 * * *\end{array}$ & $\begin{array}{c}376.340 \\
150.747 * * *\end{array}$ \\
\hline
\end{tabular}

Notes: The dependent variable is the bootstrap DEA efficiency score (Efficiency) from the first stage. Bootstrapped standard errors are in parentheses. 2000 bootstrapping replications were used. Constant is omitted to conserve space.

$*$ denotes significance at $10 \%$ level, $* *$ at $5 \%$ level, and $* * *$ at $1 \%$ level

Finally in Table 5 we present the results of estimating equation (3) and testing for Proposition 3. For comparative purposes we also present both results from a bootstrap Tobit and a bootstrap Truncated regression. The results in columns (1) and (3), in which IT is measured as total expenses in IT, and in columns (2) and (4), in which the IT variable (IT pc) 
covers only IT expenses for direct patient care, confirm the result obtained previously; that the relationship between IT and efficiency has a U-shaped form even after controlling for quality.

Additionally, the results show that the relationship between quality and efficiency is linear, but only positive for the case of complications. Controlling for quality in the IT-efficiency relationship implies that the threshold level at which the impact of IT on hospital efficiency becomes positive is lower than that obtained for Table 4 . In this case the level of IT expenditure at which the minimum occurs is of thirteen and a half million dollars (i.e. $\exp (2.605)=13.5)$. In our sample, there are 59 hospitals above that threshold level of IT investment. As previously, these hospitals are characterized by being large, mostly urban and of teaching character.

Regarding the direct impact of quality on efficiency the results are rather mixed. On the one hand, results in Table 5 show that hospital quality measured in terms of mortality has no significant direct effect on efficiency. On the other hand, when quality is measured in terms of complications there seems to be a significant positive effect; a lower adjusted risk of complications (i.e. higher quality) leads to higher efficiency ${ }^{5}$.

\footnotetext{
${ }^{5}$ This result is confirmed ever after controlling for the adjusted risk of mortality (column 3) or even after we use non-adjusted measures of quality (results not shown but are available upon request).
} 
Table 5. The relationship between IT, Quality and Efficiency

\begin{tabular}{|c|c|c|c|c|}
\hline \multirow{3}{*}{$\begin{array}{l}\text { Dependent } \\
\text { Variable }\end{array}$} & \multicolumn{2}{|c|}{ Bootstrap Tobit } & \multicolumn{2}{|c|}{ Bootstrap Truncated Regression } \\
\hline & Efficiency & Efficiency & Efficiency & Efficiency \\
\hline & (1) & (2) & (3) & (4) \\
\hline \multirow[t]{2}{*}{ IT (in logs) } & $-0.089 * * *$ & & $-0.051 * * *$ & \\
\hline & $(0.027)$ & & $(0.012)$ & \\
\hline \multirow[t]{2}{*}{$I T^{2}($ in logs $)$} & $0.018 * * *$ & & $0.010 * * *$ & \\
\hline & $(0.007)$ & & $(0.003)$ & \\
\hline \multirow{2}{*}{ RAMI } & -0.001 & -0.005 & -0.007 & -0.009 \\
\hline & $(0.039)$ & $(0.039)$ & $(0.025)$ & $(0.025)$ \\
\hline \multirow[t]{2}{*}{$R A C I$} & $-0.072 * * *$ & $-0.068 * * *$ & $-0.038 * *$ & $-0.037 * *$ \\
\hline & $(0.025)$ & $(0.025)$ & $(0.017)$ & $(0.017)$ \\
\hline \multirow[t]{2}{*}{$I T \_p c($ in $\log s)$} & & $-0.049 * * *$ & & $-0.031 * * *$ \\
\hline & & $(0.016)$ & & $(0.008)$ \\
\hline \multirow[t]{2}{*}{$I T p c^{2}($ in $\log s)$} & & $0.017 * * *$ & & $0.010 * * *$ \\
\hline & & $(0.006)$ & & $(0.003)$ \\
\hline \multirow[t]{2}{*}{$C M I$} & -0.012 & -0.018 & 0.030 & 0.025 \\
\hline & $(0.045)$ & $(0.044)$ & $(0.031)$ & $(0.031)$ \\
\hline \multirow[t]{2}{*}{ Urban } & -0.017 & -0.019 & -0.023 & -0.024 \\
\hline & $(0.021)$ & $(0.021)$ & $(0.016)$ & $(0.015)$ \\
\hline \multirow{2}{*}{ Teaching } & 0.004 & 0.003 & 0.003 & 0.003 \\
\hline & $(0.017)$ & $(0.018)$ & $(0.013)$ & $(0.013)$ \\
\hline \multirow[t]{2}{*}{ rel_avgwg } & $-0.056 * * *$ & $-0.055 * * *$ & $-0.032 * * *$ & $-0.032 * * *$ \\
\hline & $(0.018)$ & $(0.018)$ & $(0.011)$ & $(0.011)$ \\
\hline \multirow[t]{2}{*}{$o c c \_r t$} & $0.002 * * *$ & $0.002 * * *$ & $0.001 * * *$ & $0.001 * * *$ \\
\hline & $(0.000)$ & $(0.000)$ & $(0.000)$ & $(0.000)$ \\
\hline \multirow[t]{2}{*}{ rev_ppd } & $0.022 * * *$ & $0.020 * * *$ & $0.010 * * *$ & $0.009 * * *$ \\
\hline & $(0.004)$ & $(0.005)$ & $(0.002)$ & $(0.002)$ \\
\hline \multirow[t]{2}{*}{ Calos } & $-0.044 * *$ & $-0.038 * *$ & -0.014 & -0.012 \\
\hline & $(0.019)$ & $(0.019)$ & $(0.013)$ & $(0.012)$ \\
\hline \multirow[t]{2}{*}{ Medium-sized } & $-0.071^{*}$ & $-0.084 * *$ & $-0.041^{*}$ & $-0.048 * *$ \\
\hline & $(0.036)$ & $(0.033)$ & $(0.022)$ & $(0.022)$ \\
\hline \multirow{2}{*}{ Large-sized } & -0.049 & $-0.073 *$ & -0.023 & -0.035 \\
\hline & $(0.040)$ & $(0.038)$ & $(0.025)$ & $(0.024)$ \\
\hline \multirow[t]{2}{*}{ Year 2005} & $-0.034 * *$ & $-0.036 * * *$ & $-0.021 * *$ & $-0.022 * *$ \\
\hline & $(0.014)$ & $(0.014)$ & $(0.009)$ & $(0.009)$ \\
\hline \multirow[t]{2}{*}{ Sigma } & $0.118 * * *$ & $0.120 * * *$ & $0.087 * * *$ & $0.088 * * *$ \\
\hline & $(0.006)$ & $(0.006)$ & $(0.003)$ & $(0.003)$ \\
\hline Log likelihood & 74.952 & 70.536 & 382.087 & 379.823 \\
\hline Wald $\chi^{2}$ & 184.896 & 175.925 & 155.115 & 165.930 \\
\hline
\end{tabular}

Notes: The dependent variable is the bootstrap DEA efficiency score (Efficiency) from the first stage. Bootstrapped standard errors are in parentheses. 2000 bootstrapping replications were used. Constant is omitted to conserve space.

$*$ denotes significance at $10 \%$ level, ** at $5 \%$ level, and *** at $1 \%$ level 


\section{Discussion of Findings}

Our estimation results indicate that IT has a direct impact on quality (Proposition 1); IT impacts efficiency in a U-shaped form (Proposition 2); and IT and quality positively impact efficiency but after a threshold level of IT investment have been surpassed (Proposition 3). Proposition 3 complements Proposition 1 and Proposition 2 and suggests that IT's impact on efficiency is moderated by quality. The conventional wisdom is that efficiency manifests before quality because process changes generally seek to simplify steps and lower costs. We find that although IT directly influences quality (in terms of mortality); its impact on efficiency is moderated by quality (in terms of complications). Therefore, quality appears central to the investment of IT in hospitals.

Our findings suggest that IT investment's influence on increasing quality is not at the cost of efficiency. In other words, hospitals can achieve 'have it all' with both higher efficiency and higher quality. Our findings shed further light on how IT influences quality and efficiency. We find that the impact of IT investment on efficiency is non-linear. Indeed, there appears to be a 'sweet spot' at which efficiency is optimal. This suggests that IT's contribution to efficiency, for example through automation, reaches diminishing returns, a finding that is of practical relevance to hospital administrators.

Our findings are consistent with conclusions of previous studies in operations management and healthcare (Hendricks and Singhal, 1996; Lewis, 2011) in suggesting that firms that have obtained quality improvements also perform better than similar firms in operations based measures. Previous IT business value research has also deployed quality variables to assess the impact of IT investments on business outcomes (Myers et al., 1997, Wilcocks and Lester, 1997). Business process redesign (BPR), aiming on quality improvements, has also been examined in IT business value research (Grover et al., 1998). Our findings shed further light 
on previous findings that found that higher levels of IT investment are associated with reduced operating expenses in acute care hospitals in the US but only after hospitals have reached a threshold level of investment (Beard et al., 2007). This study revealed that at lower initial levels of IT investment, operating costs increased with incremental investment and that hospitals with higher IT investments tend to have a lower mortality rate (as a measure of quality).

Similarly, Menon et al. (2009) developed a model to assess the longitudinal impact of two types of IT investment on US hospital output and medical labor productivity. They found that clinical IT lags improved hospital output in the short run and administrative IT was negatively associated with organizational performance in the short run but positively associated with these performance measures over the long run. More recently, a report from Fitch Ratings (Lewis, 2011) concluded that investments in healthcare IT and improved clinical quality measures had a significant impact on a hospital's operating performance. In our findings, while IT's influence on quality is significant on hospital mortality, we did not find a significant relationship with hospital "complications", our second measure of quality. 


\section{Concluding Remarks}

Our findings shed light upon how IT investments influence quality and operational efficiency among US hospitals. We find that IT investments lead to higher service quality and also play a moderating role in achieving operational efficiency. IT investments improve operational efficiency but up to a certain point.

\subsection{Research Implications}

There is a sizable literature investigating the business value of IT for different industries. However, the business value of IT in healthcare is still to be fully investigated (Devaraj et al., 2013; Haddad and Wickramasinghe, 2014). Our paper contributes to ongoing investigations of IT business value in healthcare by answering two important research questions "i) Can hospitals improve their operational efficiency as well as healthcare quality by investments in information systems?", and "ii) What is the optimal balance of efficiency and quality relative to IT investment? In other words, "What is the 'sweet spot' of IT investment at which both operational efficiency and service quality are maximized?" We identified the interplay of efficiency and quality and the characteristics of the hospitals that can better take advantage of their IT investments.

Several researchers argue in order to understand the effects of technology on performance, the technology's process-level impacts need to be examined (Hitt and Brynjolfsson, 1996, Rai et al., 2006, Sambamurthy et al., 2003). Process-level impacts provide a means for understanding the underlying mechanisms through which the impacts of IT are causally related to performance. However, our macro production function view contributes to the existing literature because it is important for hospital administrators to understand the overall impact of IT investment and its contribution to performance. These decisions influence the 
allocation of funding. Previous IT value research has focused on how to extract the most from information systems "after" this allocation has been made.

In addition to seeking answers to the above research questions, this paper contributes to the literature with an alternative methodological approach based upon a two-stage double bootstrap data envelopment analysis (DEA), in line with Simar and Wilson (2007). Despite the popularity of DEA to measure efficiency in hospitals, few studies have used bootstrapping to account for measurement errors in estimates, the exceptions being Staat (2006) and Araújo et al. (2014), among others.

\subsection{Policy Implications}

During the last few years, healthcare spending in developed countries had grown much faster than GDP (OECD 2013). In 2013, healthcare spending was 7-18\% of GDP in developed countries (OECD 2013; Martin et al., 2014). Recent studies suggest if increases in healthcare costs are inevitable, the focus should shift from cost reduction to improving healthcare quality (Thompson et al., 2014). In a recent Washington Post article on quality of healthcare delivered by hospitals, Holy Cross Hospital was listed as one of the best and Johns Hopkins was not. "The report is not a ranking of hospitals; it is not based on unscientific data such as reputation," Mark R. Chassin, president of the commission said. "But the specific actions that it measures add up to millions of opportunities "to provide the right care to patients at American hospitals," he said ${ }^{6}$.

Since the new initiatives are beginning to evaluate healthcare quality, an understanding of factors that can lead to improved quality is important. For instance, the Health Information

\footnotetext{
${ }^{6}$ http://www.washingtonpost.com/national/health-science/holy-cross-2-other-area-hospitals-make-topperformer-list/2012/09/20/5cf2bba2-0334-11e2-9b24-ff730c7f6312 story.html?hpid=z2
} 
Technology for Economic and Clinical Health Act encourages hospitals to improve operational efficiency and healthcare quality by adopting healthcare IT. Hospitals will receive Medicare (a U.S. government program for elderly citizens) and Medicaid incentive payments when they use healthcare IT in order to achieve "meaningful use" objectives with respect to healthcare quality.

Our findings will inform healthcare managers to make IT investments in pursuit of quality and optimal improvements in operations. In doing so, we hope that the healthcare managers will have realistic expectations from the influence of IT and these findings will encourage them to make optimal IT investments.

\subsection{Limitations and Suggestions for Future Research}

There are several limitations to our approach that are worth noting and can offer fertile areas of future research. First, our data encompasses two years (2004-2005) and a great amount of change in healthcare information systems domain (such as the HITECH Act) has taken place during the last seven years. Therefore, these findings need to be demonstrated over a longer period and it would be interesting if future research could collect the more recent data and compare the findings with findings of the current study. Future studies with longitudinal data need to examine impact of IT on hospital efficiency and quality. The second limitation of our study is IT's mixed impact on quality (i.e. mortality but not complications). Future studies may consider research designs that trace the path of quality, for example, from adverse events to readmissions and mortality. 


\section{Acknowledgements}

The authors convey their deep gratitude to Professor Rajiv Kohli from the Mason School of Business, College of William \& Marry for his help to access the data and his continuous mentorship.

\section{References}

Abernathy, W.J., Clark, K.B., and Kantrow A.M. (1981). The new industrial competition. Harvard Business Review 59(5), 68-81.

Araújo C., Barros C.P., Wanke P. (2014). Efficiency determinants and capacity issues in Brazilian for-profit hospitals. Health Care Management Science, 17(2), 126-138.

Atkinson, S.E., and Wilson P.W. (1995). Comparing mean efficiency and productivity scores from small samples: A bootstrap methodology. Journal of Productivity Analysis 6(4), 137-152.

Barua, A., Lee, B., and Winston A. (1996). The Calculus of Reengineering. Information Systems Research 7(4), 409-428.

Barros, C.P., and Peypoch N. (2009). An evaluation of European airlines' operational performance. International Journal of Production Economics 122 (6), 525-533

Blegen, M.A., Goode, C.J., and Reed L. (1998). Nurse staffing and patient outcomes. Nursing Research 47(1), 43-50.

Blegen, M.A., and Vaughn T. (1998). A multisite study of nurse staffing and patient occurrences. Nursing Economic 16(4), 196-203.

Büyüközkan, G., Çifçi, G., and Güleryüz, S. (2011). Strategic analysis of healthcare service quality using fuzzy AHP methodology, Expert Systems with Applications 38(8), 9407-9424.

Büyüközkan, G., and Çifçi, G. (2012). A combined fuzzy AHP and fuzzy TOPSIS based strategic analysis of electronic service quality in healthcare industry, Expert Systems with Applications 39(3), 2341-2354.

Brynjolfsson, E., and Hitt L. (1996). Paradox lost? Firm-level evidence on the returns to information systems spending, Management Science 42(4), 541-558.

Brynjolfsson, E., and Hitt L. (2000). Beyond computation: Information technology, organization transformation and business performance. Journal of Economic Perspectives, 14(4), 23-48.

Charnes, A., Cooper, W.W., and Rhodes E. (1978). Measuring the efficiency of decision making units. European Journal of Operational Research 2(4), 429-444.

Charnes, A., Cooper, W.W., Golany, B., Seiford, L., and Stutz J. (1985), Foundations of data envelopment analysis for Pareto-Koopmans efficient empirical production functions, Journal of Econometrics, 30(2), 91-107.

Chaudhry B., Wang J., and Wu S. (2006). Systematic review: impact of health information technology on quality, efficiency, and costs of medical care, Ann Intern Med, 144(4), 742-752.

Carey K., and Burgess J. (1999). On measuring the hospital cost/quality trade-off. Health Economics 8(4), 509-520.

Clement J.P., Valdmanis V.G., Bazzoli, G.J., Zhao, M., and Chukmaitov A. (2008). Is more better? An analysis of hospital outcomes and efficiency with a DEA model of output congestion, Health Care Management Science. 11(1), 67-77. 
Congressional Budget Office. Letter to Nancy Pelosi from Douglas Elmendorf, director, CBO [Internet]. Washington (DC): $\mathrm{CBO}$; 2010 Mar 20. Available from: http://www.cbo.gov/ftpdocs/113xx/docll379/AmendReconProp.pdf

Crosby, P.B. (1979). Quality is Free, New York: McGraw-Hill

Das, S., Yaylacicegi, U. and Menon, N.M. (2011). The Effect of Information Technology Investments in Healthcare: A Longitudinal Study of its Lag, Duration, and Economic Value. IEEE Transactions on Engineering Management. 58(1), 67-86.

Datamonitor Report (2008). Technology Trends: Analyzing Global Enterprise IT Budgets 2008. Available from www.datamonitor.com.

Davenport, T.H., and Glaser J, (2002). Just-in-time-delivery comes to knowledge management, Harvard Business Review, 80(7) 107.

De Nicola A., Gitto S., Mancuso P. (2012). Uncover the predictive structure of healthcare efficiency applying a bootstrapped data envelopment analysis. Expert System with Applications, 39(12), 10495-10499.

Deming W.E. (1986). Out of the Crisis, MIT Press.

Devaraj, S., and Kohli R. (2000). Information technology payoff in the health-care industry: A longitudinal study. Journal of Management Information Systems 16(4) 41-67.

Devaraj, S., Ow, T., Kohli, R. (2013). Examining the Impact of Information Technology and Patient Flow on Healthcare Performance: A Theory of Swift and Even Flow (TSEF) Perspective. Journal of Operations Management 31(4), 181-192.

Dranove, D., and Satterthwaite M.A. (1998). The Industrial Organization of Health Care markets, Handbook of Health Economics.

Emrouznejad, A., and De Witte, K. (2010). COOPER-framework: A unified process for nonparametric projects. European Journal of Operational Research 207(3) 1573-1586.

Farrell, M. (1957). The Measurement of Productive Efficiency. Journal of the Royal Statistics Society Series A 120 (3), 253-81.

Fine, C.H. (1986). Quality improvements and learning in productive systems. Management Science. 32 (10), 1301-1315.

Folland, S., Goodman A., and Stano M. (2010). The economics of health and health care (6th ed.). Upper Saddle River, NJ. Prentice Hall.

Garvin, D.A. (1983). Quality on the line. Harvard Business Review 61(4) 65-75.

Giraleas, D., Emrouznejad, A., and Thanassoulis E. (2012). Productivity change using growth accounting and frontier-based approaches - Evidence from a Monte Carlo analysis. European Journal of Operational Research 222(3), 673-683

Grover, V. Teng, J. Segars, A., Fiedler, K. (1998). The influence of information technology diffusion and business process change on perceived productivity. The IS executive's perspective. Information and Management 34(3), 141-159.

Haberfelde, M., Bedecarre, D., and Buffum, M. (2005). Nurse-sensitive patient outcomes: an annotated bibliography. Journal of Nursing Administration 35(6), 293-299.

Hendricks K.B., and Singhal, V.R. (1996). Quality awards and the market value of the firm: an empirical investigation. Management Science 42(3), 415-436.

Hendricks K.B., and Singhal, V.R. (2000). Firm characteristics, total quality management, and financial performance. Journal of Operations Management 42(6), 238 1-17. 
Hendricks, K., Singhal, V.R. (1997). Does implementing an effective TQM program actually improve operating performance? Empirical evidence from firms that have won quality awards. Management Science 43(9), 1258-1274.

Herzlinger R. (2006). Why Innovation in Healthcare is so Hard? Harvard Business Review, 84(5), 5866.

Himmelstein D.U., Wright, A., and Woolhandler S. (2010). Hospital Computing and the Costs and Quality of Care: A National Study. American Journal of Medicine 123(1), 40-46.

Hollingsworth, B. (2003). Non-parametric and parametric applications measuring efficiency in health care. Health Care Management Science 6(4) 203-18.

Hvenegaard A., Arendt, J.N., Street, A., and Gyrd-Hansen, D. (2011). Exploring the relationship between costs and quality: does the joint evaluation of costs and quality alter the ranking of Danish hospital departments? European Journal of Health Economics 12(6), 541-551.

Jha, A.K., C.M. DesRoches, E.G. Campbell, K. Donelan, S.R. Rao, T.G. Ferris, A. Shields, S. Rosenbaum, D. Blumenthal. (2009). Use of electronic health records in US hospitals. New England Journal of Medicine 360(16), 1628-1638.

Jones, S.S., R.S. Rudin, T. Perry, P.G. Shekelle. (2014). Health information technology: An updated systematic review with a focus on meaningful use. Annual Internal Medicine, 160(1), 48-54.

Juran, J.M., and Gryna F.M. (1980). Quality Planning and Analysis. McGraw-Hill, New York.

IDC Report. (2008). Western Europe Healthcare Sector IT Spending Forecast Update, 2007-2011.

Kirigia, J.M., Emrouznejad A., Vaz, R.G., Bastiene, H., and Padayachy, J. (2008). A comparative assessment of performance and productivity of health centres in Seychelles. International Journal of Productivity and Performance Management, 57(1), 72-92.

Lewis N. (2011). Health IT Boosts Bottom Line For Hospitals. Information Week, 23 May 2011. Available from http://www.informationweek.com/news/healthcare/EMR/229625385

Lin, T.T., Lee, C-C., and Chiu, T-T. (2009). Application of DEA in analyzing a bank's operating performance. Expert Systems with Applications, 36, 8883-8891.

Litvak, E., and Bisognano M. (2011). More Patients, Less Payment: Increasing Hospital Efficiency In The Aftermath Of Health Reform. Health Affairs 30(1), 76-80.

Lovell, C.K. (1993). Production frontiers and productive efficiency. In Fried, A. O., Lovell, A. K., and Schmidt, S. S., editors, The Measurement of Productive Efficiency, chapter 1, pages $3-67$. Oxford University Press.

Mango, P.D., and Shapiro L.A. (2001). Hospitals get serious about operations, The McKinsey Quarterly. 2(2), 74-85.

Martin, A.B., M. Hartman, L. Whittle, A. Catlin. (2014). National health spending in 2012: Rate of health spending growth remained low for the fourth consecutive year. Health Affairs 33(1), 6777.

Merkert, R., Smith, A., and Nash, C.A. (2010). Benchmarking of Train Operating Firms - A Transaction Cost Efficiency Analysis. Transportation Planning and Technology 33(1) 35-53.

Menon, N., U. Yaylacicegi, A. Cezar. (2009). Differential effects of the two types of information systems: A hospital-based study. Journal of Management Information Systems. 26(1) 297-316

Menon, N. and Kohli, R. (2013). Blunting Damocles' Sword: A Longitudinal Model of Healthcare IT Impact on Malpractice Insurance Premium and Quality of Patient Care. Information Systems Research 24(4), 918-932. 
Mittal, N., and Nault B. (2009). Investments in Information Technology: Indirect Effects and Information. Information Systems Research 20(1), 56-70.

Myers, B., Kappelman, L., and Prybutok, V. (1997). A comprehensive model for assessing the quality and productivity of the information system function: toward a contingency theory for information systems assessment University of North Texas, Working paper, ISRC-WP-19970101.

Morey R.C., Fine, D.J., Loree, S.W., Retzlaff-Roberts, D.L., and Tsubakitani, S. (1992). The trade-off between hospital cost and quality of care. An exploratory empirical analysis. Medical Care 30(5), 677-698.

Maniadakis N., Hollingsworth, B., and Thanassoulis, E. (1999). The impact of the internal market on hospital efficiency, productivity and service quality. Health Care Management Science 2(1), $75-$ 85 .

McKay, N.L., and Deily, M.E. (2005). Comparing high- and low-performing hospitals using risk adjusted excess mortality and cost inefficiency. Health Care Manage Review 30(4), 347-360.

McCloskey, D.N. (1998), The Rhetoric of Economics (second edition), The University of Wisconsin Press, Madison.

Nayar, P., and Ozcan, Y.A. (2008). Data envelopment analysis comparison of hospital efficiency and quality. Journal of Medical Systems 32(3), 193-99.

OECD (2013). Health at a Glance 2013: OECD Indicators. OECD Publishing. Retrieved February 20, 2014, from http://www.oecd.org/els/health-systems/Health-at-a-Glance-2013.pdf

Picone, G.A. (2003). Does Higher Hospital Cost Imply Higher Quality of Care? Review of Economics and Statistics 85(1), 51.62 .

Rai, A., Patnayakuni, R., and Seth, N. (2006). Firm Performance Impacts of Digitally Enabled Supply Chain Integration Capabilities. MIS Quarterly 30(2), 225-246.

Salge, T.O. (2011). A behavioral model of innovative search: Evidence from public hospital services. Journal of Public Administration Research and Theory 21(1), 181-210.

Southern California Evidence-based Practice Center. Evidence report/ technology assessment number 132: Costs and benefits of health information technology. AHRQ Publication No. 06-E006, April 2006.

Sambamurthy, V., Bharadwaj, A., and Grover, V. (2003). Shaping Agility through Digital Options: Reconceptualizing the role of IT in Contemporary Firms. MIS Quarterly 27(2), 237-263.

Simar, L., and Wilson, P. (1998). Sensitivity of efficiency scores: How to bootstrap in Non-parametric frontier models. Management Sciences 44(1), 49-61.

Simar, L. and P.W. Wilson (2007). Estimation and Inference in Two-Stage, Semi-Parametric Models of Production Processes. Journal of Econometrics, 136(1), 31-64.

Simar, L. and P.W. Wilson (2011). Two-Stage DEA: Caveat emptor. Journal of Productivity Analysis 36(4), 205-218.

Staat, M. (2006). Efficiency of hospitals in Germany: a DEA-bootstrap approach. Applied Economics 38(19), 2255-2263.

Thompson S., Kohli R., Jones C., Lovejoy N., McGraves-Lloyd K., and Finison K., (Forthcoming). Evaluating Health Care Delivery Reform Initiatives in the Face of "Cost Disease" Population Health Management.

Truffer C.J., Keehan, S., Smith, S., Cylus, J., Sisko, A., and Poisal. J.A. (2010). Health spending projections through 2019: the recession's impact continues. Health Affairs 29(3) 522-9. 
Wilcocks, L., and Lester, S. (1997). In search of information technology productivity: assessment issues, Journal of the Operational Research Society 48(11) 1082-1094.

Womack J., Byrne, A., Flume, O., Kaplan, G., and Toussaint, J. (2005). Going Lean in Health Care. Cambridge, Mass. Institute for Healthcare Improvement.

Wu, I-L., and Hu, Y-P (2012). Examining Knowledge Management Enabled Performance for Hospital Professionals: A Dynamic Capability View and the Mediating Role of Process Capability, Journal of the Association for Information Systems 13(12), 976-999.

Xue, M., and Harker, P.T. (1999). Obtaining a Full Ranking of DMUs in Super Efficiency DEA Models with Infeasible Subproblems. Working paper, Wharton Financial Institutions Center, Philadelphia, PA. 